\title{
Early Warning System of Risk in Dairy Cows with Inactive Ovaries
}

\author{
Chang Zhao, Shi Shu, Jiang Zhang, Yunlong Bai, Shuhan Sun, Yuxi Song, Cheng Xia* \\ College of Animal Science and Veterinary Medicine, Heilongjiang Bayi Agricultural University, Daqing, China \\ Email: *277863347@qq.com
}

How to cite this paper: Zhao, C., Shu, S. Zhang, J., Bai, Y.L., Sun, S.H., Song, Y.X. and Xia, C. (2018) Early Warning System of Risk in Dairy Cows with Inactive Ovaries. Journal of Biosciences and Medicines, 6, 74-88.

https://doi.org/10.4236/jbm.2018.611008

Received: July 30, 2018

Accepted: November 16, 2018

Published: November 19, 2018

\begin{abstract}
The incidence of Inactive ovaries of dairy cows in China is relatively high. There is no complete early warning system for the occurrence of ovarian quiescence in clinical cows. This test provides early warning indicators for clinical prediction of ovary cessation in dairy cows. This experiment selected blood samples of dairy cows from 60 to 90 days postpartum in the inactive ovaries group and control group. Differential proteins were selected on the basis of proteomics, three energy indexes: AST, Glu, NEFA. Four reproductive hormones: E2, $\mathrm{P} 4, \mathrm{FSH}, \mathrm{LH}$, and four differentially expressed proteins: IGFBP-2, AHSG, APO-A4, and RBP-4. Key enzyme activities: ALDOB, LDHB, ITIH3, GPX3, SPAM1, PKM2. The ELISA test kit was used to detect the content and activity of the above markers in the test bovine serum. Through correlation analysis, binary logistic regression modeling and ROC analysis, a single indicator early warning technique for APOA4 and ITIH3 was established. The early warning values were APOA4 $>28.825 \mu \mathrm{g} / \mathrm{L}$ and ITIH3 > $195.07 \mathrm{ng} / \mathrm{L}$. A multi-index early warning system based on potential biomarkers of APOA4 + ITIH3 and APOA4 + ITIH3 + E2 was established. The former had an early warning value of: APOA4 > $19.55 \mu \mathrm{g} / \mathrm{I}$; ITIH3 $>$ $191.14 \mathrm{ng} / \mathrm{L}$; the latter has an early warning value: APOA4 $>47.56 \mu \mathrm{g} / \mathrm{L}$, ITIH4 > $187.80 \mathrm{ng} / \mathrm{L}, \mathrm{E} 2<69.63 \mathrm{ng} / \mathrm{L}$.
\end{abstract}

\section{Keywords}

Inactive Ovaries of Dairy Cows, APOA4, ITIH3, E2, ROC

\section{Introduction}

Ovarian quiescence in dairy cows occurs when the follicles appear on the surface of the ovary, and even earlier, stagnant. This hinders the first step in the post-partum pregnancy of the cow during the postpartum period, which results 
in an extension of the cow's calving interval [1]. Severe dairy cows will be eliminated in advance because of their reduced breeding performance and lactation performance, causing significant economic losses to dairy farms. In the previous lab, iTRAQ/LC-MS/MS technology was used to study the expression of GPX3, SCGB1D, and PKM2 in dairy cattle's quiescent serum proteomics. ADIPOQ, AHSG, APOA4, FETUB, ALDOB, SPAM1, LDHB, RBP4, IGFBP2 The expression of ITIH3 and GLYCAM1 was up-regulated, and AST, Glu, NEFA, E2, P4, FSH, LH, IGFBP-2, AHSG, APO-A4, RBP-4, ALDOB, LDLHB, ITIH3, GPX3, SPAM1, and PKM2 related factors were determined. Ovarian quiescence has a significant correlation.

At present, there is a bit research on early warning systems for common diseases in dairy cattle in China. The use of biomarkers screened by proteomics technology at home and abroad to establish a disease risk early warning system has become an important method and tool for monitoring the risk of disease. Lin et al. [2]. Used proteomics, mass spectrometry, and ELISA methods combined with statistical receiver operating characteristic curve (ROC) analysis to screen and identify differentially expressed proteins in human nasopharyngeal carcinoma. Determination of biomarker markers. Xinhuan Xiao [3] also used a combination of proteomics and ROC analysis to determine that a protein can diagnose early postmortem ovarian quiescence in dairy cows. However, because the differential proteins screened by multiple platforms of proteomics complement each other, and ROC analysis can be used for multi-monitoring and early warning of diseases, this study has carried out multi-index joint warning of disease risk.

At present, there is no complete warning system for the occurrence of ovarian static in dairy cows. This experiment provides an early warning indicator for the prediction of ovarian static in cows.

\section{Materials and Methods}

\subsection{Test Animals}

This experiment selected an intensive cattle farm in Heilongjiang, China. Dairy cows were fed a full-mixed diet (TMR) consisting of 8 - $9 \mathrm{~kg}$ of concentrate, $17-20 \mathrm{~kg}$ of silage, $3.5-4.0 \mathrm{~kg}$ of hay, and $300-400 \mathrm{~g}$ of fat. Its nutritional level is: DM55.60\%, crude protein $16 \%$, net milk production $7.322 \mathrm{MJ} / \mathrm{kg}$, fat $5.60 \%$, NDF39.10\%, ADF20.30\%, calcium $180 \mathrm{~g}$, phosphorus $116 \mathrm{~g}$. The basic information of dairy cows is shown in Table 1, on the basis of which the two groups of cows are followed to 60 - 90 days postpartum. The external performances are observed $60 \mathrm{~d}$ after delivery and a rectal examination or B-ultrasound examination is performed to monitor the development of follicles. Based on this examination, the abnormal cows were excluded from the study. Finally, 35 cows were selected from the ovaries of the ovaries-free group (IO group) and the healthy control group (CON group). 
Table 1. The basic information of test animals from two groups.

\begin{tabular}{cccc}
\hline Mean index ( \pm standard deviation $)$ & IO $(\mathrm{N}=50)$ & CON $(\mathrm{N}=50)$ & p-value \\
\hline Postnatal days & $72.90(8.322)$ & $73.82(9.064)$ & 0.735 \\
Follicular diameter $(\mathrm{mm})$ & $2.25(1.37)$ & $10.82(2.30)$ & $0.000^{* *}$ \\
Age & $3.06(1.21)$ & $3.19(1.35)$ & 0.755 \\
Fetal times & $1.75(0.91)$ & $1.19(1.06)$ & 0.607 \\
BSC & $2.66(0.25)$ & $2.80(0.18)$ & 0.053 \\
Daily milk production (kg/day) & $34.16(12.53)$ & $33.04(7.11)$ & 0.721 \\
BHBA (mmol/L) & $0.61(0.14)$ & $0.48(0.16)$ & 0.073 \\
\hline
\end{tabular}

\subsection{Detection Indicators}

All experimental cow blood samples were tested for concentrations of the following indicators in the blood 60 - 90 days postpartum. The kits used in the experiments were purchased from Nanjing Jinyibai Company and tested by ELISA.

Energy Index: Aspartate aminotransferase (AST), Glucosamine (Glu), Non-free fatty acids (NEFA);

Reproductive hormone: E2, P4, FSH, LH;

Differential protein content: IGFBP-2, AHSG, APO-A4, RBP-4;

Key enzyme activities: ALDOB, LDHB, ITIH3, GPX3, SPAM1, PKM2.

\subsection{Data Processing}

According to the results of the energy index test, a difference analysis was conducted between the two groups. Then, the energy index, reproductive hormones, differentially expressed proteins, key enzymes and ovarian quiescence were established to establish Pearson correlation analysis, and regression analysis was used to determine the energy index's early warning effect on the occurrence of ovarian static.

\subsection{Establishment of an Early Warning System for the Risk of Disease}

According to the results, ROC analysis was applied to indicators that were significantly related to ovarian static. Through the results of ROC analysis, a single early warning indicator (biomarker) that can be used for risk of inactive ovaries, as well as cutoff values, sensitivity, and specificity, are determined to determine the best early warning system and establish a single indicator disease risk early warning system.

According to the confirmation of a single indicator, based on the optimal forecast indicator, other indicators are added in sequence to perform multiple forecasting. According to the combination of multiple indicators, use probability calculations to determine the coefficients of multiple indicators for disease prediction, apply coefficients for ROC analysis, determine multiple early warning indicators (biomarkers) and cutoff values that can be used for risk of ovarian 
static, determine the best early warning system established a multi-index joint disease risk early warning system.

\section{Results}

\subsection{The Level of Blood Energy Indicators}

The results of the blood energy index tests of cows (CON) in the inactive ovaries group (IO) and the healthy control group are shown in Table 2 .

According to the energy index test results, there was no significant difference between the two groups in AST, Glu and NEFA ( $p>0.05$ ). This shows that the energy metabolism of ovarian stationary cows is normal.

\subsection{Blood Reproductive Hormone Levels}

The results of the test on blood reproductive hormones of dairy cows in the ovarian static group and the healthy control group are shown in Table 3.

According to the analysis of the test results of reproductive hormones, we can see that among the four indicators of reproductive hormones detected between the two groups, there was only a significant difference between the two groups $(\mathrm{p}<0.05)$.

\subsection{The Level of Major Differential Proteins and Key Enzymes in Blood}

Table 4 shows the levels of 10 major differential proteins and key enzyme assays in the blood of dairy cows in the quiescent group and the healthy control group.

Table 2. Serum levels of energy and liver function parameters from two groups.

\begin{tabular}{cccc}
\hline Detection Indicator & IO $(\mathrm{N}=35)$ & CON $(\mathrm{N}=35)$ & $\mathrm{p}$ \\
\hline AST (U/L) & $92.06 \pm 17.95$ & $98.94 \pm 23.26$ & 0.189 \\
Glu (mmol/L) & $3.75 \pm 1.40$ & $3.65 \pm 0.55$ & 0.686 \\
NEFA (mmol/L) & $0.21 \pm 0.17$ & $0.26 \pm 0.15$ & 0.150 \\
\hline
\end{tabular}

Note: ${ }^{*}$ indicates that there is a significant difference between the two groups $(\mathrm{p}<0.05)$; ${ }^{*}$ indicates that there is a very significant difference between the two groups $(\mathrm{p}<0.01)$; if there is no shoulder note, the index is in both groups. There was no significant difference between the two groups $(p>0.05)$.

Table 3. Serum levels of reproductive hormones from two groups.

\begin{tabular}{cccc}
\hline Detection Indicator & IO $(\mathrm{N}=35)$ & CON $(\mathrm{N}=35)$ & $\mathrm{p}$ \\
\hline $\mathrm{E} 2(\mathrm{ng} / \mathrm{L})$ & $60.24 \pm 26.66$ & $75.11 \pm 24.03$ & $0.017^{\star}$ \\
$\mathrm{P} 4(\mathrm{ng} / \mathrm{L})$ & $138.39 \pm 83.54$ & $137.56 \pm 79.10$ & 0.966 \\
$\mathrm{E}_{2} / \mathrm{P}_{4}$ & $0.59 \pm 0.34$ & $0.75 \pm 0.53$ & 0.148 \\
$\mathrm{FSH}(\mathrm{IU} / \mathrm{L})$ & $4.23 \pm 1.68$ & $5.15 \pm 2.80$ & 0.101 \\
$\mathrm{LH}(\mathrm{ng} / \mathrm{L})$ & $15.22 \pm 10.33$ & $19.76 \pm 11.20$ & 0.144 \\
\hline
\end{tabular}

Note: ${ }^{*}$ indicates that there is a significant difference between the two groups $(\mathrm{p}<0.05) ;{ }^{*}$ indicates that there is a very significant difference between the two groups $(\mathrm{p}<0.01)$; if there is no shoulder note, the index is in both groups. There was no significant difference between the two groups $(p>0.05)$. 
Table 4. Serum levels of different proteins and key enzymes from two groups.

\begin{tabular}{cccc}
\hline Detection Indicator & IO $(\mathrm{N}=35)$ & CON $(\mathrm{N}=35)$ & $\mathrm{p}$ \\
\hline IGFBP2 $(\mu \mathrm{g} / \mathrm{L})$ & $42.36 \pm 20.43$ & $36.52 \pm 11.32$ & 0.144 \\
AHSG $(\mathrm{ng} / \mathrm{L})$ & $1520.28 \pm 506.54$ & $1280.98 \pm 466.86$ & $0.044^{*}$ \\
APOA4 $(\mu \mathrm{g} / \mathrm{L})$ & $42.10 \pm 15.99$ & $30.25 \pm 9.89$ & $0.000^{* *}$ \\
RBP4 $(\mu \mathrm{g} / \mathrm{L})$ & $15.15 \pm 5.84$ & $12.16 \pm 3.65$ & $0.013^{*}$ \\
ALDOB $(\mathrm{ng} / \mathrm{L})$ & $711.73 \pm 159.41$ & $613.87 \pm 132.87$ & $0.007^{* *}$ \\
LDHB $(\mathrm{U} / \mathrm{L})$ & $1117.60 \pm 237.22$ & $1024.37 \pm 148.00$ & 0.053 \\
ITIH3 $(\mathrm{ng} / \mathrm{L})$ & $181.55 \pm 32.19$ & $157.21 \pm 24.06$ & $0.001^{\star *}$ \\
GPX3 (ng/L) & $307.35 \pm 180.69$ & $378.95 \pm 246.29$ & 0.170 \\
SPAM1 (ng/mL) & $409.99 \pm 168.58$ & $351.52 \pm 145.39$ & 0.125 \\
PKM2 (ng/L) & $478.36 \pm 121.43$ & $501.80 \pm 215.43$ & 0.577 \\
\hline
\end{tabular}

Note: ${ }^{*}$ indicates that there is a significant difference between the two groups $(\mathrm{p}<0.05)$; ${ }^{* *}$ indicates that there is a very significant difference between the two groups ( $p<0.01$ ); if there is no shoulder note, the index is in both groups. There was no significant difference between the two groups $(p>0.05)$.

According to the results of key differential proteins and key enzyme assays, APOA4, ALDOB, and ITIH3 were significantly different between the two groups $(\mathrm{p}<0.01)$. The ovarian quiescence group was higher than the healthy control group; AHSG and RBP4 existed between the two groups. Significant difference $(\mathrm{p}<0.05)$.

\subsection{Correlation Analysis of Energy Index, Reproductive Hormones and Key Different Proteins, Key Enzymes, and Occurrence of Ovarian Metastasis}

The results of all testing indicators were analyzed using the Pearson correlation coefficient in the statistical analysis software. The results of the analysis were shown in Table 5.

\subsection{The Establishment of Binary Logistic Regression and the Determination of Early Warning Indicators}

According to the classification of relevant detection indicators, two modules were established to perform binary logistic regression on the data to determine the degree of regression fit and the determination of early warning indicators.

1) Model I

Model I is mainly based on the results of serum reproductive hormone indicators for the determination of binary logistic regression and early warning indicators. According to Table 6, the chi-square of the model is 4.841. According to the significance (0.05) and the degree of freedom (df), the chi-squared value can be calculated using the CHIINV (significance, degree of freedom) in EXCEL. The settlement is CHIINV $(0.05,8)=15.507$ and the chi-square statistic is less than the critical value of the chi-square.

According to the analysis results in Table 7, the model has a good prediction 
Table 5. Correlations analysis among all parameters from groups of dairy cows.

\begin{tabular}{|c|c|c|c|c|c|c|c|c|c|c|c|c|c|}
\hline & & IO & AST & GLU & NEFA & E2 & $\mathrm{P} 4$ & $\mathrm{E} 2 / \mathrm{P} 4$ & FSH & $\mathrm{LH}$ & IGFBP2 & SPAM1 & PKM2 \\
\hline \multirow{2}{*}{ IO } & $\mathrm{R}$ & 1 & 0.166 & -0.049 & 0.176 & $0.285^{*}$ & -0.005 & 0.175 & 0.197 & 0.209 & -0.177 & -0.185 & 0.068 \\
\hline & $\mathrm{p}$ & & 0.17 & 0.686 & 0.146 & 0.017 & 0.966 & 0.148 & 0.101 & 0.082 & 0.144 & 0.125 & 0.577 \\
\hline \multirow{2}{*}{ AST } & $\mathrm{R}$ & 0.166 & 1 & -0.077 & -0.102 & 0.018 & 0.026 & -0.192 & 0.158 & 0.104 & 0.062 & 0.041 & -0.002 \\
\hline & $\mathrm{p}$ & 0.17 & & 0.529 & 0.403 & 0.879 & 0.828 & 0.112 & 0.191 & 0.393 & 0.608 & 0.734 & 0.99 \\
\hline \multirow{2}{*}{ GLU } & $\mathrm{R}$ & -0.049 & -0.077 & 1 & -0.021 & 0.027 & -0.079 & -0.013 & -0.121 & -0.089 & -0.075 & -0.098 & -0.148 \\
\hline & $\mathrm{p}$ & 0.686 & 0.529 & & 0.865 & 0.822 & 0.515 & 0.913 & 0.318 & 0.464 & 0.536 & 0.418 & 0.222 \\
\hline \multirow{2}{*}{ NEFA } & $\mathrm{R}$ & 0.176 & -0.102 & -0.021 & 1 & $0.244^{\star}$ & $0.288^{*}$ & 0.022 & 0.019 & $0.338^{\star *}$ & -0.109 & 0.13 & -0.063 \\
\hline & $\mathrm{p}$ & 0.146 & 0.403 & 0.865 & & 0.042 & 0.016 & 0.854 & 0.877 & 0.004 & 0.37 & 0.284 & 0.602 \\
\hline \multirow{2}{*}{ E2 } & $\mathrm{R}$ & $0.285^{\star}$ & 0.018 & 0.027 & $0.244^{*}$ & 1 & 0.129 & $0.357^{\star *}$ & $0.525^{\star *}$ & $0.448^{\star *}$ & -0.088 & $0.323^{* *}$ & 0.222 \\
\hline & $\mathrm{p}$ & 0.017 & 0.879 & 0.822 & 0.042 & & 0.286 & 0.002 & 0 & 0 & 0.47 & 0.006 & 0.065 \\
\hline \multirow{2}{*}{$\mathrm{P} 4$} & $\mathrm{R}$ & -0.005 & 0.026 & -0.079 & $0.288^{*}$ & 0.129 & 1 & $-0.691^{* *}$ & $0.385^{\star *}$ & $0.426^{* *}$ & 0.209 & $0.238^{*}$ & 0.225 \\
\hline & $\mathrm{p}$ & 0.966 & 0.828 & 0.515 & 0.016 & 0.286 & & 0 & 0.001 & 0 & 0.083 & 0.047 & 0.061 \\
\hline \multirow{2}{*}{$\mathrm{E} 2 / \mathrm{P} 4$} & $\mathrm{R}$ & 0.175 & -0.192 & -0.013 & 0.022 & $0.357^{\star *}$ & $-0.691^{\star *}$ & 1 & -0.099 & -0.189 & -0.221 & -0.094 & -0.153 \\
\hline & $\mathrm{p}$ & 0.148 & 0.112 & 0.913 & 0.854 & 0.002 & 0 & & 0.417 & 0.118 & 0.066 & 0.438 & 0.205 \\
\hline \multirow{2}{*}{ FSH } & $\mathrm{R}$ & 0.197 & 0.158 & -0.121 & 0.019 & $0.525^{\star *}$ & $0.385^{\star *}$ & -0.099 & 1 & $0.547^{* *}$ & 0.104 & $0.353^{* *}$ & $0.475^{\star *}$ \\
\hline & $\mathrm{p}$ & 0.101 & 0.191 & 0.318 & 0.877 & 0 & 0.001 & 0.417 & & 0 & 0.391 & 0.003 & 0 \\
\hline \multirow{2}{*}{$\mathrm{LH}$} & $\mathrm{R}$ & 0.209 & 0.104 & -0.089 & $0.338^{* *}$ & $0.448^{* *}$ & $0.426^{* *}$ & -0.189 & $0.547^{\star *}$ & 1 & 0.061 & $0.442^{\star *}$ & $0.437^{\star *}$ \\
\hline & $\mathrm{p}$ & 0.082 & 0.393 & 0.464 & 0.004 & 0 & 0 & 0.118 & 0 & & 0.615 & 0 & 0 \\
\hline \multirow{2}{*}{ IGFBP2 } & $\mathrm{R}$ & -0.177 & 0.062 & -0.075 & -0.109 & -0.088 & 0.209 & -0.221 & 0.104 & 0.061 & 1 & $0.347^{\star *}$ & 0.204 \\
\hline & $\mathrm{p}$ & 0.144 & 0.608 & 0.536 & 0.37 & 0.47 & 0.083 & 0.066 & 0.391 & 0.615 & & 0.003 & 0.091 \\
\hline \multirow{2}{*}{ AHSG } & $\mathrm{R}$ & $-0.242^{*}$ & 0.018 & 0.031 & 0.229 & $0.395^{\star *}$ & $0.295^{\star}$ & -0.074 & $0.433^{* *}$ & $0.490^{* *}$ & $0.238^{*}$ & $0.744^{* *}$ & $0.370^{* *}$ \\
\hline & $\mathrm{p}$ & 0.044 & 0.884 & 0.797 & 0.057 & 0.001 & 0.013 & 0.543 & 0 & 0 & 0.047 & 0 & 0.002 \\
\hline \multirow{2}{*}{ APOA4 } & $\mathrm{R}$ & $-0.412^{\star *}$ & 0.17 & 0.069 & 0.148 & 0.092 & 0.225 & -0.152 & 0.146 & 0.151 & 0.107 & $0.449^{* *}$ & 0.108 \\
\hline & $\mathrm{p}$ & 0 & 0.159 & 0.573 & 0.22 & 0.447 & 0.061 & 0.21 & 0.229 & 0.212 & 0.38 & 0 & 0.371 \\
\hline \multirow{2}{*}{ RBP4 } & $\mathrm{R}$ & $-0.297^{\star}$ & -0.038 & -0.106 & 0.165 & 0.065 & 0.217 & -0.117 & -0.114 & 0.079 & 0.194 & $0.311^{* *}$ & 0.125 \\
\hline & $\mathrm{p}$ & 0.013 & 0.754 & 0.383 & 0.172 & 0.593 & 0.072 & 0.335 & 0.348 & 0.513 & 0.107 & 0.009 & 0.304 \\
\hline \multirow{2}{*}{ ALDOB } & $\mathrm{R}$ & $-0.320^{\star *}$ & -0.066 & $-0.237^{\star}$ & 0.087 & 0.117 & $0.268^{*}$ & -0.15 & 0.19 & $0.352^{\star *}$ & $0.359^{* *}$ & $0.365^{\star \star}$ & 0.124 \\
\hline & $\mathrm{p}$ & 0.007 & 0.588 & 0.048 & 0.472 & 0.335 & 0.025 & 0.215 & 0.116 & 0.003 & 0.002 & 0.002 & 0.306 \\
\hline \multirow{2}{*}{ LDHB } & $\mathrm{R}$ & -0.233 & $0.369^{* *}$ & 0.058 & -0.128 & -0.001 & 0.046 & -0.117 & 0.025 & -0.095 & 0.157 & 0.205 & -0.028 \\
\hline & $\mathrm{p}$ & 0.053 & 0.002 & 0.635 & 0.29 & 0.993 & 0.703 & 0.333 & 0.839 & 0.432 & 0.196 & 0.089 & 0.821 \\
\hline \multirow{2}{*}{ ITIH3 } & $\mathrm{R}$ & $-0.398^{\star *}$ & -0.001 & -0.142 & 0.068 & 0.234 & 0.11 & -0.123 & 0.165 & 0.222 & 0.124 & $0.299^{*}$ & 0.17 \\
\hline & $\mathrm{p}$ & 0.001 & 0.995 & 0.239 & 0.574 & 0.051 & 0.364 & 0.312 & 0.171 & 0.065 & 0.305 & 0.012 & 0.16 \\
\hline \multirow{2}{*}{ GPX3 } & $\mathrm{R}$ & 0.166 & 0.116 & -0.104 & $0.255^{\star}$ & $0.419^{\star *}$ & 0.202 & -0.055 & $0.453^{\star *}$ & $0.534^{\star *}$ & 0.172 & $0.580^{* *}$ & $0.623^{* *}$ \\
\hline & $\mathrm{p}$ & 0.17 & 0.34 & 0.39 & 0.033 & 0 & 0.094 & 0.649 & 0 & 0 & 0.154 & 0 & 0 \\
\hline \multirow{2}{*}{ SPAM1 } & $\mathrm{R}$ & -0.185 & 0.041 & -0.098 & 0.13 & $0.323^{* *}$ & $0.238^{*}$ & -0.094 & $0.353^{* *}$ & $0.442^{* *}$ & $0.347^{\star \star}$ & 1 & $0.387^{* *}$ \\
\hline & $\mathrm{p}$ & 0.125 & 0.734 & 0.418 & 0.284 & 0.006 & 0.047 & 0.438 & 0.003 & 0 & 0.003 & & 0.001 \\
\hline \multirow{2}{*}{ PKM2 } & $\mathrm{R}$ & 0.068 & -0.002 & -0.148 & -0.063 & 0.222 & 0.225 & -0.153 & $0.475^{\star *}$ & $0.437^{\star *}$ & 0.204 & $0.387^{\star *}$ & 1 \\
\hline & $\mathrm{p}$ & 0.577 & 0.99 & 0.222 & 0.602 & 0.065 & 0.061 & 0.205 & 0 & 0 & 0.091 & 0.001 & \\
\hline
\end{tabular}

Note: $\mathrm{R}$ represents the Pearson correlation coefficient, positive is a positive correlation, negative is a negative correlation, shoulder ${ }^{*}$ indicates significant correlation $(\mathrm{p}<0.05)$, shoulder ${ }^{*}$ indicates extremely significant correlation $(\mathrm{p}<0.01)$, no shoulder Note that there is no significant correlation ( $\left.\mathrm{p}>0.05\right)$. 
effect on ovary quiescence, which is $62.9 \%$, and the prediction of healthy cows is $571 \%$. This shows that the model can predict ovarian static to some extent.

According to the analysis results in Tables 8-9, if the variable E2 is removed from the model, the significance of the change is $0015<0.05$. This shows that E2 is significantly associated with prevention of ovarian quiescence and cannot be removed.

2) Model II

Model II determines the binary logistic regression and early warning indicators based on the results of serum key differentiating proteins and key enzymes (Table 10).

According to the analysis results in Table 11, it can be seen that APOA4 is better for warning to healthy cows than ovary stationary cows; after adding GPX3, both groups of warnings are improved, the total percentage is $80 \%$; and further progress in adding RBP4 will reduce the early warning effect. $78.6 \%$; further progress in joining ITIH3 resulted in a noticeable increase in early warning effectiveness, both at $80 \%$; and finally at SPAM1, the total percentage of

Table 6. Hosmer and Leme show test.

\begin{tabular}{cccc}
\hline Step & Bangla & df & Sig. \\
\hline 1 & 4.841 & 8 & 0.774 \\
\hline
\end{tabular}

Table 7. Classification table.

\begin{tabular}{cccccc}
\hline & & \multicolumn{3}{c}{ Predicted } \\
\cline { 3 - 4 } & & & Group & Percentage correction \\
\cline { 3 - 5 } \multicolumn{2}{c}{ Observed } & IO & CON & 62.9 \\
Step 1 & IO & 22 & 13 & 57.1 \\
& CON & 15 & 20 & 60 \\
\hline
\end{tabular}

Table 8. Model if term removed.

\begin{tabular}{cccccc}
\hline & Variable & $\begin{array}{c}\text { Log likelihood } \\
\text { of the model }\end{array}$ & $\begin{array}{c}\text { Changes in the } \\
\text { log-likelihood of }-2\end{array}$ & df & $\begin{array}{c}\text { Change of } \\
\text { significance }\end{array}$ \\
\hline Step 1 & $\mathrm{E}_{2}$ & -48.52 & 5.889 & 1 & 0.015 \\
\hline
\end{tabular}

Table 9. Variables not in the equation.

\begin{tabular}{ccccc}
\hline & & Score & df & Sig. \\
\hline Step 1 & $\mathrm{P}_{4}$ & 0.124 & 1 & 0.725 \\
Variable & $\mathrm{E}_{2} / \mathrm{P}_{4}$ & 0.465 & 1 & 0.495 \\
& $\mathrm{FSH}$ & 0.26 & 1 & 0.610 \\
& $\mathrm{LH}$ & 0.659 & 1 & 0.417 \\
& Presidential measurement & 2.071 & 4 & 0.723 \\
\hline
\end{tabular}


Table 10. Hosmer and Leme show test.

\begin{tabular}{cccc}
\hline Step & Bangla & df & Sig. \\
\hline 1 & 4.841 & 8 & 0.774 \\
2 & 3.604 & 8 & 0.891 \\
3 & 2.263 & 8 & 0.972 \\
4 & 5.452 & 8 & 0.708 \\
5 & 4.55 & 8 & 0.804 \\
\hline
\end{tabular}

Table 11. Classification table.

\begin{tabular}{|c|c|c|c|c|}
\hline & & \multicolumn{3}{|c|}{ Predicted } \\
\hline & & & & Percentage \\
\hline \multicolumn{2}{|c|}{ Observed } & IO & $\mathrm{CON}$ & correction \\
\hline \multirow[t]{2}{*}{ Step 1} & IO & 21 & 14 & 60 \\
\hline & $\mathrm{CON}$ & 10 & 25 & 71.4 \\
\hline \multicolumn{4}{|c|}{ Total percentage } & 65.7 \\
\hline \multirow[t]{2}{*}{ Step 2} & IO & 25 & 10 & 71.4 \\
\hline & $\mathrm{CON}$ & 9 & 26 & 74.3 \\
\hline \multicolumn{4}{|c|}{ Total percentage } & 74.3 \\
\hline \multirow[t]{2}{*}{ Step 3} & IO & 28 & 7 & 80 \\
\hline & $\mathrm{CON}$ & 7 & 27 & 77.1 \\
\hline \multicolumn{4}{|c|}{ Total percentage } & 78.6 \\
\hline \multirow[t]{2}{*}{ Step 4} & IO & 28 & 7 & 80 \\
\hline & $\mathrm{CON}$ & 7 & 28 & 80 \\
\hline \multicolumn{4}{|c|}{ Total percentage } & 80 \\
\hline \multirow[t]{3}{*}{ Step 5} & IO & 28 & 7 & 80 \\
\hline & $\mathrm{CON}$ & 8 & 27 & 77.1 \\
\hline & \multicolumn{2}{|c|}{ Total percentage } & & 78.6 \\
\hline
\end{tabular}

warnings was $78.6 \%$. This shows that the model can predict ovarian static to some extent.

According to the results of Table 12, it can be seen that if the variables APOA4, GPX3, RBP4, ITIH3, and SPAM1 were removed in the model, the significance of the changes, although they were successively increased, was still less than 0.05 . Note that POA4, GPX3, RBP4, ITIH3, and SPAM1 are significantly related to the occurrence of ovarian quiescence and cannot be removed.

According to Table 13, the significance of removing IGFBP2, AHSG, ALDOB, LDHB, and PKM2 was greater than 0.05, indicating that IGFBP2, AHSG, ALDOB, LDHB, and PKM2 could not be used as predictors of ovarian static. According to the establishment of Model II, APOA4, GPX3, RBP4, ITIH3, and SPAM1 can predict ovarian quiescence in the energy index, while IGFBP2, 
Table 12. Model if term removed.

\begin{tabular}{|c|c|c|c|c|c|}
\hline & Variable & $\begin{array}{l}\text { Log likelihood } \\
\text { of the model }\end{array}$ & $\begin{array}{c}\text { Changes in the } \\
\text { log-likelihood of }-2\end{array}$ & $\mathrm{df}$ & $\begin{array}{l}\text { Change of } \\
\text { significance }\end{array}$ \\
\hline Step 1 & APOA4 & -48.52 & 13.891 & 1 & 0 \\
\hline \multirow[t]{2}{*}{ Step 2} & APOA4 & -47.515 & 26.597 & 1 & 0 \\
\hline & GPX3 & -41.575 & 14.716 & 1 & 0 \\
\hline \multirow[t]{3}{*}{ Step 3} & APOA4 & -42.277 & 23.367 & 1 & 0 \\
\hline & RBP4 & -34.217 & 7.246 & 1 & 0.007 \\
\hline & GPX3 & -40.322 & 19.456 & 1 & 0 \\
\hline \multirow[t]{4}{*}{ Step 4} & APOA4 & -36.953 & 17.351 & 1 & 0 \\
\hline & RBP4 & -30.903 & 5.25 & 1 & 0.022 \\
\hline & ITIH3 & -30.594 & 4.633 & 1 & 0.031 \\
\hline & GPX3 & -37.631 & 18.708 & 1 & 0 \\
\hline \multirow[t]{5}{*}{ Step 5} & APOA4 & -31.484 & 10.754 & 1 & 0.001 \\
\hline & RBP4 & -27.579 & 2.944 & 1 & 0.086 \\
\hline & ITIH3 & -28.67 & 5.125 & 1 & 0.024 \\
\hline & GPX3 & -37.442 & 22.669 & 1 & 0 \\
\hline & SPAM1 & -28.277 & 4.34 & 1 & 0.037 \\
\hline
\end{tabular}

AHSG, ALDOB, LDHB, and PKM2 cannot.

According to all the analysis results, among the detected reproductive hormones, major differentially expressed proteins and key enzymes, E2, APOA4, GPX3, RBP4, ITIH3, and SPAM1 can be used as indices for early warning of ovarian rest in dairy cows

\subsection{Risk Warning System of Single Indicator}

In this experiment, ROC analysis was performed on the above-mentioned early warning indicators, and the Youden value was calculated based on the experimental results. Youden $=$ sensitivity + specificity -1 . Select the critical value of the indicator based on the Youden value. The results are shown in Table 14, and the ROC analysis curve is shown in Figure 1.

According to the ROC analysis results, the better indicators of early warning effectiveness are APOA4, ITIH3, E2, SPAM1, RBP4, and GPX3. The area under the curve is $0.747,0.711,0.673,0.646,0.637$ and 0.586 , respectively. This shows that all eight early warning indicators can provide early warning of ovarian static. The early warning thresholds for each indicator were: APOA4 $>28.825 \mu \mathrm{g} / \mathrm{L}$, ITIH3 > $195.07 \mathrm{ng} / \mathrm{L}$, E2 < $48.19 \mathrm{ng} / \mathrm{L}$, SPAM1 $>294.255 \mathrm{ng} / \mathrm{ml}, \mathrm{RBP} 4>15.215$ $\mu \mathrm{g} / \mathrm{L}$, and GPX3 $<441.43 \mathrm{ng} / \mathrm{L}$.

\subsection{Multiple Indicators Joint Risk Early Warning System}

According to the single-indicator warning results, although 8 indicators can provide early warning of ovarian inactivity, in order to explore better warning 
Table 13. Variables not in the equation.

\begin{tabular}{|c|c|c|c|c|}
\hline & variable & Score & $\mathrm{df}$ & Sig. \\
\hline \multirow[t]{10}{*}{ Step 1} & IGFBP2 & 0.942 & 1 & 0.332 \\
\hline & AHSG & 0.002 & 1 & 0.968 \\
\hline & RBP4 & 2.482 & 1 & 0.115 \\
\hline & ALDOB & 1.905 & 1 & 0.167 \\
\hline & LDHB & 1.521 & 1 & 0.217 \\
\hline & ITIH3 & 6.587 & 1 & 0.01 \\
\hline & GPX3 & 7.371 & 1 & 0.007 \\
\hline & SPAM1 & 0.04 & 1 & 0.842 \\
\hline & PKM2 & 1.65 & 1 & 0.199 \\
\hline & Presidential measurement & 21.016 & 9 & 0.013 \\
\hline \multirow[t]{9}{*}{ Step 2} & IGFBP2 & 1.903 & 1 & 0.168 \\
\hline & AHSG & 3.082 & 1 & 0.079 \\
\hline & RBP4 & 6.734 & 1 & 0.009 \\
\hline & ALDOB & 1.328 & 1 & 0.249 \\
\hline & LDHB & 3.329 & 1 & 0.068 \\
\hline & ITIH3 & 6.616 & 1 & 0.01 \\
\hline & SPAM1 & 6.705 & 1 & 0.01 \\
\hline & PKM2 & 0.03 & 1 & 0.863 \\
\hline & Presidential measurement & 18.573 & 8 & 0.017 \\
\hline \multirow[t]{8}{*}{ Step 3} & IGFBP2 & 0.849 & 1 & 0.357 \\
\hline & AHSG & 1.538 & 1 & 0.215 \\
\hline & ALDOB & 0.292 & 1 & 0.589 \\
\hline & LDHB & 3.174 & 1 & 0.075 \\
\hline & ITIH3 & 4.69 & 1 & 0.03 \\
\hline & SPAM1 & 3.759 & 1 & 0.053 \\
\hline & PKM2 & 0.002 & 1 & 0.967 \\
\hline & Presidential measurement & 13.049 & 7 & 0.071 \\
\hline \multirow[t]{7}{*}{ Step 4} & IGFBP2 & 1.187 & 1 & 0.276 \\
\hline & AHSG & 1.674 & 1 & 0.196 \\
\hline & ALDOB & 0.065 & 1 & 0.798 \\
\hline & LDHB & 3.784 & 1 & 0.052 \\
\hline & SPAM1 & 4.068 & 1 & 0.044 \\
\hline & PKM2 & 0.305 & 1 & 0.581 \\
\hline & Presidential measurement & 8.678 & 6 & 0.193 \\
\hline \multirow[t]{6}{*}{ Step 5} & IGFBP2 & 0.885 & 1 & 0.347 \\
\hline & AHSG & 0.785 & 1 & 0.376 \\
\hline & ALDOB & 0.092 & 1 & 0.761 \\
\hline & LDHB & 2.862 & 1 & 0.091 \\
\hline & PKM2 & 0.684 & 1 & 0.408 \\
\hline & Presidential measurement & 5.457 & 5 & 0.363 \\
\hline
\end{tabular}


Table 14. The results of single warning indicators from ROC analysis.

\begin{tabular}{ccccc}
\hline Variable & Sensitivity (\%) & Specificity (\%) & Area under the curve & Demarcation \\
\hline $\mathrm{E}_{2}$ & 91.4 & 42.9 & 0.673 & $<48.19 \mathrm{ng} / \mathrm{L}$ \\
APOA4 & 88.6 & 57.1 & 0.747 & $>28.825 \mu \mathrm{g} / \mathrm{L}$ \\
RBP4 & 42.9 & 82.9 & 0.637 & $>15.215 \mu \mathrm{g} / \mathrm{L}$ \\
ITIH3 & 40 & 97.1 & 0.711 & $>195.07 \mathrm{ng} / \mathrm{L}$ \\
GPX3 & 28.6 & 94.3 & 0.586 & $<441.43 \mathrm{ng} / \mathrm{L}$ \\
SPAM1 & 88.6 & 42.9 & 0.646 & $>294.255 \mathrm{ng} / \mathrm{ml}$ \\
\hline
\end{tabular}

Note: $\mathrm{E}_{2}$ : Estradiol; APOA4: Apolipoprotein A-IV; RBP4: Retinol-binding protein 4; ITIH3: Inter-alpha-trypsin inhibitor heavy chain H3; GPX3: Glutathione peroxidase; SPAM1: Hyaluronidase.

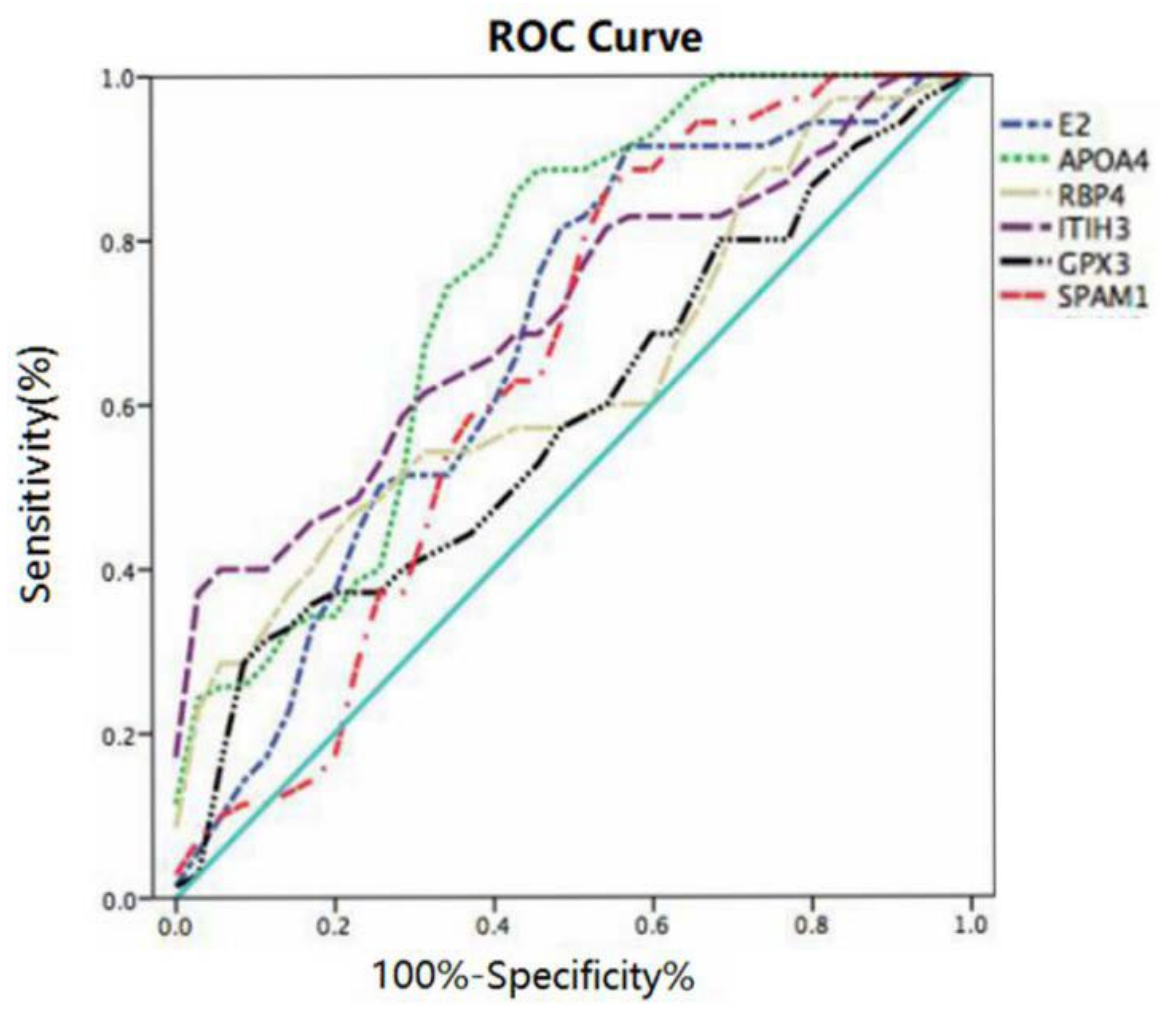

Note: E2 is estradiol; APOA4 is apolipoprotein 4; RBP4 is retinol binding protein 4; ITIH3 is Inter- $\alpha$-trypsin inhibitor heavy chain H3; GPX3 is glutathione peroxidase; SPAM1 Hyaluronidase.

Figure 1. ROC curve.

effects, the experiment is based on APOA4 with the best warning effect, followed by the addition of the best indicators for other warnings to fit, and then Perform ROC analysis and establish multiple indicators for early warning of ovarian static. The results are shown in Table 15, and the ROC analysis chart is shown in Figure 2.

According to the multi-index ROC analysis results, proper combination of various indicators can effectively improve the effect of disease early warning. The sensitivity and specificity of APOA4 + ITIH3 combined with early warning were $65.7 \%$ and $80 \%$, respectively. After increasing E2, the sensitivity increased 
Table 15. The results of multiple warning indicators from ROC analysis.

\begin{tabular}{cccc} 
Variable & Sensitivity (\%) & Specificity (\%) & $\begin{array}{c}\text { Area under the } \\
\text { curve }\end{array}$ \\
APOA4 + ITIH3 & 65.7 & 80 & 0.792 \\
APOA4 + ITIH3 + E 2 & 82.9 & 62.9 & 0.816 \\
APOA4 + ITIH3 + E $_{2}+$ SPAM1 & 82.9 & 62.9 & 0.816 \\
APOA4 + ITIH3 + E $_{2}+$ SPAM1 + RBP4 & 82.9 & 62.9 & 0.816 \\
APOA4 + ITIH3 + E $_{2}+$ SPAM1 + RBP4 + GPX3 & 82.9 & 62.9 & 0.816 \\
\hline
\end{tabular}

Note: E2 is estradiol; APOA4 is apolipoprotein 4; RBP4 is retinol binding protein 4; ITIH3 is Inter- $\alpha$-trypsin inhibitor heavy chain H3; GPX3 is glutathione peroxidase; SPAM1 Hyaluronidase.

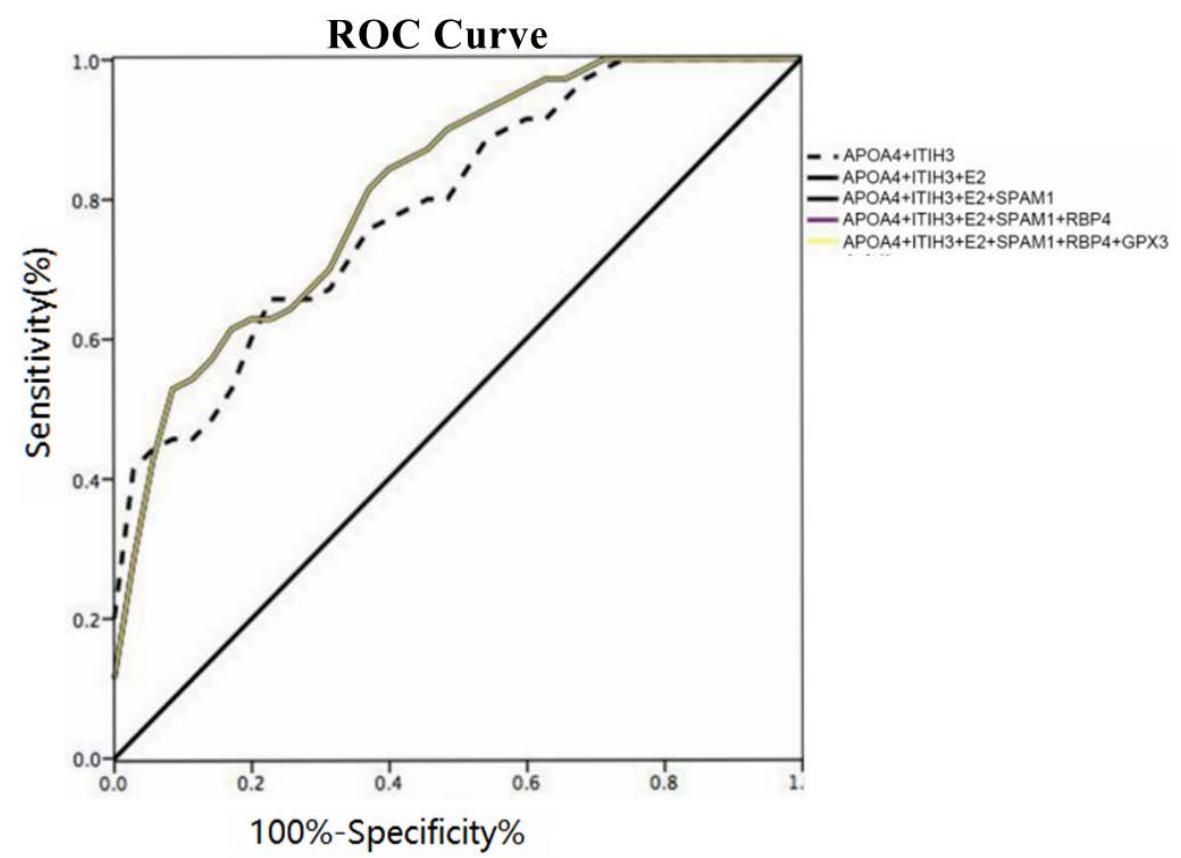

Note: Due to the fact that the area under the curve of some prediction results is the same, multiple analytical curves overlap. APOA4 is apolipoprotein 4; ITIH3 is Inter- $\alpha$-trypsin inhibitor heavy chain H3; E2 is estradiol; SPAM1 is hyaluronidase; RBP4 is retinol binding protein 4; GPX3 is glutathione Oxide enzyme.

Figure 2. ROC curve from composite warning indicators.

to $82.9 \%$ (17.2\% above float), but the specificity decreased to $62.8 \%$ (downward $17.2 \%)$. After continuing to add indicators to the model, it did not affect the effectiveness, specificity, and sensitivity of the warning. Therefore, APOA4 + ITIH3 and APOA4 + ITIH3 + E2 are the two most effective early warning modes.

After the ROC analysis based on the probability values generated by the multi-index model, the Youden value calculation is consistent with the previous experiment. The index data corresponding to the largest Youden value is the boundary value of the diagnostic model. The results are as follows:

1) APOA4 + ITIH3: APOA4 > $19.55 \mu \mathrm{g} / \mathrm{L}$, ITIH3 > $191.14 \mathrm{ng} / \mathrm{L}$;

2) $\mathrm{APOA} 4+\mathrm{ITIH} 3+\mathrm{E} 2:$ APOA4 $>47.56 \mu \mathrm{g} / \mathrm{L}$, ITIH3 > $1827.80 \mathrm{ng} / \mathrm{L}, \mathrm{E} 2<$ 
$69.63 \mathrm{ng} / \mathrm{L}$;

3) APOA4 + ITIH3 + E2 + SPAM1: APOA4 > $47.56 \mu \mathrm{g} / \mathrm{L}$, ITIH3 > 1827.80 $\mathrm{ng} / \mathrm{L}, \mathrm{E} 2<69.63 \mathrm{ng} / \mathrm{L}, \mathrm{SPAM} 1>472.07 \mathrm{ng} / \mathrm{ml}$;

4) $\mathrm{APOA} 4+\mathrm{ITIH} 3+\mathrm{E} 2+\mathrm{SPAM} 1+\mathrm{RBP} 4:$ APOA4 $>47.56 \mu \mathrm{g} / \mathrm{L}$, ITIH3 > $1827.80 \mathrm{ng} / \mathrm{L}, \mathrm{E} 2<69.63 \mathrm{ng} / \mathrm{L}, \mathrm{SPAM} 1>472.07 \mathrm{ng} / \mathrm{ml}, \mathrm{RBP} 4>16.84 \mu \mathrm{g} / \mathrm{L}$;

5) $\mathrm{APOA} 4+\mathrm{ITIH} 3+\mathrm{E} 2+\mathrm{SPAM} 1+\mathrm{RBP} 4+\mathrm{GPX} 3:$ APOA4 $>47.56 \mu \mathrm{g} / \mathrm{L}$, ITIH3 > $1827.80 \mathrm{ng} / \mathrm{L}, \mathrm{E} 2<69.63 \mathrm{ng} / \mathrm{L}, \mathrm{SPAM} 1>472.07 \mathrm{ng} / \mathrm{ml}, \mathrm{RBP} 4>16.84$ $\mu \mathrm{g} / \mathrm{L}, \mathrm{GPX} 3<456.44 \mathrm{ng} / \mathrm{L}$.

\section{Discussion}

Ovarian quiescence in cows is usually diagnosed by estrus identification 50 - 60 days after childbirth. The estrus identification method is usually to observe the estrus detection, rectal examination and B-ultrasound, and then use hormones to treat ovarian static cows. The existing problems: 1) The diagnosis of ovarian static is mostly after the occurrence; 2) The rectal examination is more stressful to dairy cows and does not meet the animal welfare requirements; 3) Hormone treatment after ovarian static, the effect is not the same, dairy hormones Residues. In view of the above-mentioned problems of quiescence in the ovaries, this study carried out early warning and analysis of the risk of ovarian static in cows from the aspects of mineral elements, energy indexes, reproductive hormones, and major differential proteins and key enzymes.

In a single indicator early warning, APOA4 and ITIH3 have a better warning effect on the risk of ovarian static. APOA4 + ITIH3 and APOA4 + ITIH3 + E2 have a better warning effect on the risk of ovarian static in multi-index early warning. It is well-known that E2 is a reproductive hormone and is directly related to ovarian disease. However, APOA4 and ITIH3, as representative substances of lipids and enzymes, have a prewarning effect on a single indicator or multi-indicator combination of ovarian static, suggesting their potential role in ovarian function and its application value.

APOA4 is a member of the apolipoprotein A1/C3/A4/A5 gene cluster [4]. APOA4 is a $46 \mathrm{kDa}$ glycoprotein that is almost exclusively produced in intestinal epithelial cells and secreted into the lymph. APOA4 was first identified as a component of chylomicrons and high-density lipoproteins. The members of the APOA4 gene cluster are involved in the metabolism of lipids and lipoproteins, and therefore participate in a variety of physiological and pathological processes in the body.

Inter- $\alpha$-trypsin inhibitor (ITI) is a blood-derived protein necessary for reproduction in females. It consists of two heavy chains (HC2 and HC3) and core protein bikunin [5]. ITIH3 can be used as a carrier of hyaluronic acid in serum or as a binding protein between hyaluronic acid and other matrix proteins to regulate the localization, synthesis, and degradation of hyaluronan necessary for cells. The only function of Bikunin in binding to ITIH3 is covalent attachment to hyaluronic acid [6], which is the main component of the extracellular matrix 
(ECM) but is also secreted into body fluids such as blood and lymph [7]. This is the reason for the detection of ITIH3 in the blood [8]. Hyaluronic acid is a high molecular weight glycosaminoglycan that exists in the ECM with high molecular weight and high hydrophilicity. The complex of serum-derived hyaluronan-associated protein (SHAP) and hyaluronic acid is bound to hyaluronic acid via the ester bond in bikunin [9]. However, no bikunin was found in the purified complex, indicating that it was released during complex formation. Studies have shown that hyaluronic acid and ITI were detected during granulocyte expansion, suggesting that ITI is important during follicular growth [10]. It is speculated that in the development of follicles, the body produces bikunin to bind ITIH3, which in turn binds hyaluronic acid, which in turn promotes the growth of follicles.

\section{Conclusion}

Based on the correlation analysis, binary logistic regression, and ROC analysis, this experiment established a single early warning index and early warning value of post-natal ovarian rest risk based on APOA4 and ITIH3; established the risk of ovarian static based on APOA4 + ITIH4 + E2 A number of early warning indicators and their early warning values; established a single index and multiple indicator early warning system for the occurrence of post-natal ovarian static in dairy cows, providing a methodological basis for future prediction of post-natal ovarian static in dairy cows.

\section{Conflicts of Interest}

The authors declare no conflicts of interest regarding the publication of this paper.

\section{References}

[1] Mazerbourg, S., Bondy, C.A., Zhou, J., et al. (2003) The Insulin-Like Growth Factor System: A Key Determinant Role in the Growth and Selection of Ovarian Follicles? A Comparative Species Study. Reproduction in Domestic Animals, 38, 247. https://doi.org/10.1046/j.1439-0531.2003.00440.x

[2] Lin, L.H., Xu, Y.W., Huang, L.S., et al. (2017) Serum Proteomic-Based Analysis Identifying Autoantibodies against PRDX2 and PRDX3 as Potential Diagnostic Biomarkers in Nasopharyngeal Carcinoma. Clinical Proteomics, 14, 6. https://doi.org/10.1186/s12014-017-9141-5

[3] Xin, H.X. (2017) Postpartum Ovarian Static Serum Proteomics Analysis and Early Warning Assessment of Energy Negative Balance Dairy Cows. Heilongjiang Bayi Agricultural University, Daqing.

[4] Dieplinger, H., Ankerst, D.P., Burges, A., et al. (2009) Afamin and Apolipoprotein A-IV: Novel Protein Markers for Ovarian Cancer. Cancer Epidemiology Biomarkers \& Prevention, 18, 1127-1133. https://doi.org/10.1158/1055-9965.EPI-08-0653

[5] Odum, L., Jessen, T.E. and Andersen, C.Y. (2001) Glycosaminoglycan-Bound and Free Inter-Alpha-Trypsin Inhibitor Components of Follicular Fluid. Zygote, 9, 283-288. https://doi.org/10.1017/S0967199401001319 
[6] Huang, L., Yoneda, M. and Kimata, K. (1993) A Serum-Derived Hyaluronan-Associated Protein (SHAP) Is the Heavy Chain of the Inter Alpha-Trypsin Inhibitor. Journal of Biological Chemistry, 268, 26725.

[7] Hamm, A., Veeck, J., Bektas, N., et al. (2008) Frequent Expression Loss of Inter-Alpha-Trypsin Inhibitor Heavy Chain (ITIH) Genes in Multiple Human Solid Tumors: A Systematic Expression Analysis. BMC Cancer, 8, 1-15. https://doi.org/10.1186/1471-2407-8-25

[8] Salustri, A. (2000) Paracrine Actions of Oocytes in the Mouse Pre-Ovulatory Follicle. International Journal of Developmental Biology, 44, 591-597.

[9] Zhao, M., Yoneda, M., Ohashi, Y., et al. (1995) Evidence for the Covalent Binding of SHAP, Heavy Chains of Inter-Alpha-Trypsin Inhibitor, to Hyaluronan. Journal of Biological Chemistry, 270, 26657-26663. https://doi.org/10.1074/jbc.270.44.26657

[10] Clarke, H.G., Hope, S.A., Byers, S., et al. (2006) Formation of Ovarian Follicular Fluid May Be Due to the Osmotic Potential of Large Glycosaminoglycans and Proteoglycans. Reproduction, 132, 119-131. https://doi.org/10.1530/rep.1.00960 